\title{
Word Stress in Qassimi Arabic: A Constraint-Based Analysis
}

\author{
Reem Mohammed Alabeeky ${ }^{1}$ \\ ${ }^{1}$ Department of English Language \& Translation, College of Arabic Language \& Social Studies, Qassim \\ University, Saudi Arabia \\ Correspondence: Reem Alabeeky, Department of English Language \& Translation, College of Arabic Language \\ \& Social Studies, Qassim University, Saudi Arabia. E-mail: noor19851@gmail.com
}

\author{
Received: October 8, $2021 \quad$ Accepted: November 20, $2021 \quad$ Online Published: December 1, 2021 \\ doi:10.5539/ijel.v12n1p98 URL: https://doi.org/10.5539/ijel.v12n1p98
}

\begin{abstract}
This study aimed to produce a formalism of word stress in Qassimi Arabic (QA), which is a sub-dialect of Najdi Arabic (NA), using a constraint-based approach. To this end, this paper investigated two main topics: The first topic explored word stress in QA. Word stress in QA, as well as in NA, is predictable; it can be determined by syllable weight and position. However, two cases do not conform to such straightforward stress rules. These cases are represented by the words: [?al.Sa.s'ir] 'afternoon' and [?a.Sa.rif] 'I know'. Derivational analysis of these exceptions shows the importance of relating the surface structures of such forms to their underlying representations. The second topic aimed to make a formalism for stress patterns in QA using optimality theory (OT). Thus, QA word stress rules and their exceptions are translated into conflicting constraints that are ranked relative to one another by the use of constraint-relation tableaux. This ranking eventually produced the following constraint-relation hierarchy: Lx $\approx \operatorname{Pr}$, SYLLABLE-INTEGRITY, TROCHAIC, FAITH-PK $>>$ NONFINAL $>>$ *[?a. $>>$ FTBIN- $\mu$, WSP, ALL-FEET-RIGHT $>>$ MAIN-RIGHT, PARSE- $\sigma$.
\end{abstract}

Keywords: optimality theory, Qassimi Arabic, word stress

\section{Introduction}

OT, as introduced by Prince and Smolensky (2004) and McCarthy and Prince (1993), is a recent grammatical framework that considers surface forms to determine the "optimal" or most harmonic form that best satisfies a set of constraints. Like in previous derivational models - Generative Grammar (Chomsky, 1965) and (Chomsky \& Halle, 1968): Principles and Parameters (Hayes, 1980) - there are a set of constraints that need to be satisfied for a particular structure to be considered well-formed. However, the substantial difference in this approach lies in that these constraints can be violated while we can still determine an output form among other forms that is well-formed or optimal.

One of the fundamental tenets of OT is that constraints intrinsically clash with one another. It then follows that to obtain the actual surface form, one of these constraints will be inevitably violated while the other is satisfied. Nevertheless, it is crucially important to decide on the constraint where the violation of which is less harmful, i.e., violating some constraints is more "serious" and could lead to ungrammaticality compared to violating other constraints. For this reason, constraints must be ranked hierarchically: higher-ranked constraints take priority over lower-ranked constraints. Eventually, a constraint-relation hierarchy is produced to define some particular linguistic feature.

Given that OT has shown some success in representing different linguistic aspects, particularly in phonology, this study aims to use the OT framework to account for primary stress patterns in QA. As a prosodic phenomenon, stress perceptually refers to the notion of prominence: that is, when a certain syllable in a word or phrase is said to be stressed, it is more 'prominent' than other syllables in the given word or phrase. Since word stress in QA is predictable as it is purely phonological, it will be researched using a constraint-based approach where the constraints governing stress patterns in QA will be clearly defined. Furthermore, at the heart of OT lies the idea that language is a system of conflicting constraints, this conflict will be resolved in QA stress patterns by constraint ranking: each constraint will be ranked relative to other constraints, and, subsequently, the whole sets of relations will be unified in a form of a constraint-relation hierarchy.

QA is a sub-dialect of NA spoken in the Qassim region, Saudi Arabia. Among Najdi dialects, QA is spoken in the northern part of Najd, and it has noticeably different phonological and morphological particularities. Therefore, - 
since the Qassim region is a vast area with a large population, the prosody and phonological features of QA are worth discussing independently as a specific variety of NA.

This paper is organized as follows: Section 2 reviews the related literature. Section 3 describes the word stress rules in QA as stated in the literature and then discusses two exceptional cases in relation to these rules. The derivation of these exceptional cases provides a justification of their stress patterns. Section 4 provides a constraint-based analysis of QA word stress patterns that accounts for these exceptional cases. Finally, Section 5 provides a conclusion and summary of the main findings.

\section{Literature Review}

\subsection{Applications of OT in Arabic}

The OT framework has been used to formulate regularities for certain linguistic aspects of Arabic. For instance, Sakarna (2013) proposed an OT-based model that can account for broken plurals in Jordanian Arabic. In addition, Btoosh (2006) used an OT-based approach to investigate syncope and epenthesis in Jordanian Arabic and shed light on issues concerning complex onsets, complex codas, and geminates. Similarly, Jarrah (2013) discussed the ranking of constraints to account for syllable structures in Madina Hijazi Arabic.

\subsection{OT and Arabic Stress Placement}

Probably, the first attempt to approach Arabic stress using the OT framework was by Al-Jarrah (2002), who set up a constraint domination relation hierarchy to account for word stress in Classical Arabic. His analysis produced the following constraint hierarchy:

TROCHAIC, MAIN-RIGHT, Lx=Pr, *NON-PRIMARY $>$ NONFINAL $(\sigma \mu \mu) \quad>\quad$ PARSE $\sigma \quad>$ NONFINAL $(\sigma \mu \mu \mu)$, FOOT-BINARITY $\mu>>$ ALL-FEET-LEFT $>>$ ALL-FEET-RIGHT

In (2008), Al-Jarrah conducted research in which he represented domination relations among constraints that account for stress in Cairene Arabic resulting in the following hierarchy:

Lx $=$ Pr, TROCHAIC, MAIN-RIGHT $>>$ PARSE $\sigma \mu \mu \mu>$ NONFINAL $>>$ PARSE $\sigma \mu \mu$, FOOT-BINARITY $\mu>>$ ALL-FEET-LEFT $>>$ ALL-FEET-RIGHT.

The above hierarchy can account for penultimate stress in words like /mam.la.ka/ 'kingdom'. Since the final syllable is extrametrical because of NONFINAL, the domination of MAIN-RIGHT allows the stress to fall on the right-most syllable.

Stress in Cairene Arabic has drawn the attention of other researchers. Among them we find Aquil (2012) and Buell and Steriade (1996). The latter used a footless strategy in which all constraints related to foot (trochaic/ foot-binarity/ parse, etc.) are factored out; instead, constraints related to mora and syllables are used.

\subsection{NA Syllabification in OT}

From an OT perspective, Algahtani (2014) has extensively investigated NA syllable structure, including phonological processes such as metathesis, epenthesis, vowel shortening, and syncope.

AlAmro (2015) has also attempted to tackle syllabification in NA within an OT framework, including issues like epenthesis, syncope, markedness of sonority hierarchy, vowel shortening, and cluster tolerance.

Regarding QA syllabification, a study by Al Motairi (2015) reached conclusions similar to the findings in Algahtani (2014). However, the difference in Al Motairi's findings is that, unlike other NA dialects, QA avoids both non-final superheavy syllables of the patterns CVVC and CVCC by epenthesis. Thus, / fa:f.hum/ 'he saw them' would be realized as / $\mathrm{fa}$ :.fu.hum/.

\subsection{Najdi Stress in OT}

In 2013, AlDweikat attempted to determine a constraint domination relation hierarchy to account for word stress in Najdi Arabic. His analysis produced the following hierarchy:

Lx $=$ Pr, SYLLABLE-INTEGRITY, PARSE- $\sigma \mu \mu \mu$, *MONOMORAIC, TROCHAIC $>$ NON-FINAL, MAIN-RIGHT $>>$ ALL-FEET-RIGHT, PARSE- $\sigma \mu(\mu)$, F $\mu \mu$ > ALL-FEET-LEFT

\section{Stress in QA}

QA, as a subdialect of NA, is considered to have an undistinguishable stress pattern from those of other NA dialects. Some works on NA stress (e.g., Prochazka, 1988; Ingham, 1994; Al Amro, 2019) stated that syllable weight and position are the clues to stress placement and agreed on the following set of ordered rules:

NA Stress Rules (henceforth NASRs): 
1) Stress falls on one of the last three syllables. Stress falls on the ultimate syllable if it is superheavy.

2) Otherwise, stress falls on the penultimate syllable if it is heavy.

3) Otherwise, stress falls on the ante-penultimate.

4) In disyllabic words: stress falls on the ultimate syllable if it is superheavy, otherwise stress falls on the first syllable.

5) Monosyllabic words must receive stress.

Nonetheless, there are two exceptions to these rules that are worth investigating. The first is found in most NA dialects, while the second is a particularity of QA. These exceptions are illustrated next.

3.1 Case 1: [?al.Sa.sir]

Consider the following set of words:
a. [?al.Sa.s'sir] 'afternoon'
b. [?al.wa.zin]'the weight'
c. [?al.Su.mir] 'the age'
d. [Pal.ba.zir] 'the child'

This set has the structure CVC.CV.CVC, which, according to NASRs should have antepenultimate stress since the ultimate is not superheavy and the penult is light. However, stress lodges on the penult. It is clear that this whole set is prefixed with the definite article '?al'. If we try to morphologically formalize a rule for this set by assuming that forms prefixed with the definite article '?al' have penultimate stress, then how can we account for stress in the following forms?
a. [?al.ka.nab] 'the sofas'
b. [?al.ma.hal] 'the place'
c. [?al.ка.nam] 'the sheep'
d. [?al.ga.har] 'the bitterness'

These forms have initial stress conforming to NASRs. The fact that there are identical Pal.CV.CVC structures but alternating stress positions makes it inappropriate to make generalizations at the surface level. Moreover, since the definite article 'Pal' is stressed in some cases and destressed in others, we might have to resort to phonological rather than morphological derivation. Let us now consider the underlying forms from which the forms in (3.1) are derived:
a. /Ral.Sas' $\mathbf{r} /$
b. /Pal.wazn/
c. /Pal.Sumr/
d. /Ral.bazr/

The underlying forms are structured CVC.CVCC where the final superheavy syllable has undergone epenthesis because the final coda cluster does not comply with the Sonority Sequencing Principle (Roca, 1994), i.e., the first consonant is less sonorous than the second consonant. The resulting structure is, therefore, CVC.CV.CVC. The question that arises now is how underlying forms can serve in deciding the stress positions of surface forms? It is already determined that the underlying CVC.CVCC has final stress. What happened here is that epenthesis has taken place, and the superheavy syllable CVCC is broken by epenthesis into CV.CVC. Nonetheless, the stressed vowel in the underlying form seems to preserve stress in the surface form. The first analysis of this was

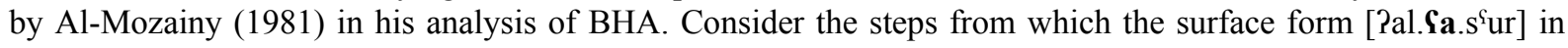
BHA is derived (Al-Mozainy, 1981, p. 137):

/Ral. Sas $^{\mathrm{T}} \mathrm{r} /$

$\begin{array}{ll}\text { Pal.९as'r } & \text { stress } \\ \text { Pal.Sa.s'ur } & \text { epenthesis }\end{array}$ 


\section{[?al. $\mathbf{a}$. s $\left.^{\mathrm{S}} \mathrm{ur}\right]$}

To conclude, despite the structural change that such forms have undergone via epenthesis, it appears that the stressed vowel in the underlying form preserves stress during the process of derivation.

\subsection{Case 2: [?a.Sa.rif]}

Consider the following set of words:
a. [?a.Sa.rif] 'I know'
b. [Pa.za.bir] 'I remember'
c. [?a.Sa.dzin] 'I knead'

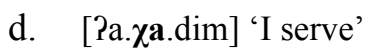

According to NASRs, the stress in CV.CV.CVC structures should fall on the antepenultimate syllable since neither the ultimate is superheavy nor the penult is heavy. On the contrary, the word set in (3.4) receives stress in the light penult. Furthermore, the syllable structure of this set is CV.CV.CVC, which is not preferable as it consists of successive light syllables (Alqahtani, 2014), and the first vowel should have undergone tri-syllabic elision. Therefore, this set contradicts stress rules as well as syllabification 'vowel deletion' rules. Now, two questions regarding stress and syllabification of these structures must be addressed: How this syllable sequence is permitted in these words? And why does the penultimate syllable receive stress? First, let us consider the underlying forms from which these words are derived:
a. /2aS.rif/
b. /2ax.bir/
c. /PaS.jin/
d. /2ax.dim/

To answer the first question, we notice that the underlying forms represent the syllable structure CVC.CVC. However, guttural consonants are not allowed in a coda position, and therefore, a resyllabification process takes place: Abboud (1979) has demonstrated that the initial syllables of coda guttural undergo two resyllabification processes. Consider, for instance, how the surface form [lha.mih] 'meat' is derived:

/laћ.mih/

/la.ћa.mih/ low vowel insertion after the guttural "epenthesis"

/ha.mih/ initial vowel deletion

[lha.mih]

This process represents that surface forms like [1ha.mih] appear with the initial cluster due to vowel deletion. However, we notice that the surface forms in (3.4) do not have this initial consonant cluster, which suggests that another process has also taken place underlyingly to prevent a complex onset. Note that each word in the list has the structure $/ \mathrm{PaC} /$ as its first syllable. This indicates that the initial consonant cluster of initial syllables of the form / $\mathrm{PC} /$ is not allowed. In fact, Al-Mozainy (1981) has introduced the rule of initial vowel epenthesis:

$\varnothing \longrightarrow[+$ syll $] / \#$ ?_C

This rule demonstrates that a $/ \mathrm{PC} /$ cluster is not acceptable and needs to be interposed by a vowel. So, here I propose the following derivation to [?a.xa.dim]:

/Rax.dim/

Pax.dim stress

2a.xa.dim epenthesis after guttural

?ұa.dim low vowel deletion and stress shift

Pa. $\chi \mathbf{a}$.dim epenthesis in the environment \# ?_C

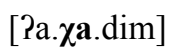

The previous analysis demonstrates how resyllabification results in a CV.CV.CVC structure. Turning to the second question regarding why the penultimate syllable receives stress, Al-Mozainy (1981) demonstrates that in 
a word like / $\mathbf{2 a}$.dim/, metathesis takes place, and, by shifting the vowel from 'before' to 'after' the guttural, the stress also shifts, forming $/ \mathbf{2} \chi \mathbf{a} \cdot \mathbf{d i m} /$. Therefore, he demonstrates that the stressed vowel, in this case, is also preserved in the surface forms. However, under the assumption that [?a.CV.CVC] structures have penultimate stress due to stress preservation during the process of derivation, we are now faced with forms that appear problematic. Consider the underlying and surface forms of the following verbs:

Underlying forms

Surface forms
a. /2a.ka.lat/
[?a.ka.lat] 'she ate'

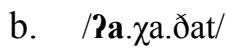
[?a.xa.ðat] 'she took'

Such forms have identical syllable structures in both the underlying and surface forms. However, they have initial stress underlyingly but are realized with penultimate stress. Oh (1998) has argued that stress in such forms cannot resort to the assumption made by Al-Mozainy (1981) that it is the underlyingly assigned stress that is preserved. Instead, he argues that, in such forms, stress assignment rules, as in NASRs, are decomposed into separate rules, and these rules are applied in order. For instance, consider how stress rules apply in the derivation process of [?a.хa.ðat]:

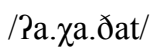

2a. $\chi$ a.ðat stress (NASRs: stress rule ' 3 ')

?xa.ðat LVD

Pxa.ðat stress (NASRs: stress rule ' 4 ')

Pa.хa.ðat epenthesis

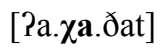

This shows that after the application of stress rule ' 3 ', the underlyingly stressed vowel is deleted due to LVD. After that, stress is reassigned by the next stress rule (stress rule ' 4 '). Finally, a vowel is epenthesized in the environment \#?_C (Oh, 1998, p. 19).

It appears that the analysis of Oh (1998) for such forms is satisfactory for two reasons: First that the underlying forms have identical syllable structures to the surface forms, and second, that the stress rules are applied in their expected order. Thus, if we adopt the analysis of Oh (1998), we would rather assume that these forms are assigned stress on the surface. Moreover, word stress in such forms is phonological rather than morphological: in (3.4) / $\mathrm{Ra}$ /is a first-person prefix, while in (3.6) it is part of the stem.

\section{OT Analysis of QA Stress}

Based on the above analysis of QA stress, in this section, we will attempt to provide a formalism for QA stress using the OT framework. In other words, NASRs, as well as exceptions to these rules, will be translated into a constraint-relation hierarchy.

\subsection{Data}

In the following dataset, syllabification and stress positioning are assigned by the author, who is a native speaker of QA. Furthermore, two native speakers of QA who also study linguistics have verified them. 
Table 1. Example word structures in QA

\begin{tabular}{|c|c|c|}
\hline $\mathrm{CVC}$ & CVC.CVCC & CVC.CV.CVC \\
\hline 1. gil 'say! (M.)' & 13. dar.rast 'I taught' & 22. mis.fi.hil 'happy' \\
\hline CV.CV & CV.CV.CVC & 23. min.gi.t'is 'cut' \\
\hline 2. $\quad$ Ga.t $t^{f} a$ 'he gave' & 14. Pa.Sa.rif 'I know' & 24. mak.ti.bih 'library' \\
\hline CV.CVC & 15. Pa.Sa.dzin 'I knead' & maz.ri.Gih 'farm' \\
\hline 3. 2a.-1ir 'it is found out that..' & CV.CVC.CVC & 26. man.$^{t}$ i.gih 'region' \\
\hline Pa.sir 'arrest' & 16. Pa.Sal.lim 'I inform' & 27. Pal.Sa.s'ir 'afternoon' \\
\hline 2a.mir 'I pass by' & 17. t'a.las.na 'we went out' & CVC.CVC.CVC \\
\hline Sa.t'at 'she gave' & ma.hat'.t'ih 'station' & 28. mak.tib.tik 'your library' \\
\hline Pa.kal 'he ate' & 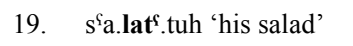 & 29. mis.tar.mal 'pre-owned' \\
\hline hi.bir 'ink' & 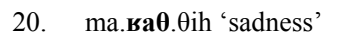 & CCV.CVC \\
\hline ma.lik 'king' & CVV.CV.CVC & 30. кni.mih 'a sheep' \\
\hline 10. ga.lam 'pen' & 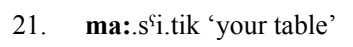 & CCV.CVC.CV(C) \\
\hline CVC.CVC & & 31. Jdza.rat.na 'our tree' \\
\hline 11. каt' t' $^{\mathrm{f}}$ ' 'she covered" & & bga.rat.hum 'their cow' \\
\hline 12. mak.tab 'office' & & \\
\hline
\end{tabular}

Note. syllables in bold are stressed.

In addition, 10 educated native speakers who were born and brought up in Qassim region were asked to produce words from SA to determine how QA speakers realize prosodic features that cannot be decided through QA word structures.

Table 2. Example word structures in SA

\begin{tabular}{|c|c|}
\hline Tri-syllabic words & Poly-syllabic words \\
\hline 1. $\quad$ sa.la.t'ah 'salad' & 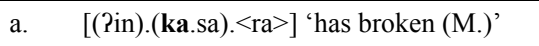 \\
\hline 2. ma.li.kah 'queen' & [(wa:).(qi.fa). $<$ tun $>$ ] 'is standing (FIM.)' \\
\hline ha.la.qah 'circlet' & {$[($ mak).(ta.ba). $<$ tuh $>]$ 'his library' } \\
\hline & {$[($ a.ja).(ra.tu). $<$ na $>]$ 'our tree’ } \\
\hline & e. $\quad[$ (ma.li). $($ ka.tu). $<$ na $>]$ 'our queen' \\
\hline & {$[(\mathrm{Pal}) .(\mathrm{mam}) .(\mathbf{l a} \cdot \mathrm{ka}) .<\mathrm{ti}>]$ 'the kingdom' } \\
\hline & g. $\quad$ (mam).la.(ka.tu). $<$ na $>$ 'our kingdom' \\
\hline & h. $\quad$ (mak).ta.(ba.tu). $<\mathrm{ki}>$ 'your library' \\
\hline & (Pad).wi.(ya.tu). $<\mathrm{ka}>$ 'your medicines' \\
\hline
\end{tabular}

\subsection{Constraints}

Here, we list the most related prosodic constraints that have been referred to in the literature:

WSP: Heavy syllables must be stressed (Prince, 1990).

PARSE- $\sigma$ : Syllables belong to feet (McCarthy \& Prince, 1993a).

MAIN-RIGHT/LEFT: Align the head-foot with the word, on the right/left edge (Tesar, 1996).

ALL-FEET-RIGHT/LEFT: Align each foot with the word, on the right/left edge (Tesar, 1996; Kager, 1999).

IAMBIC/TROCHAIC: Align the head-syllable with its foot on the right/left edge (Tesar, 1996).

NONFINAL/NONINITIAL: The final/initial syllable should not be footed (Tesar, 1996).

$\mathrm{Lx} \approx \operatorname{Pr}$ (MCat): A member of the morphological category corresponds to a prosodic word "PrWd" (Prince \& Smolensky, 2004).

${ }^{*} \sigma_{(\mu)}$ : Monomoraic syllables are not stressed (Broselow, 1992; Kager, 1999).

FTBIN: Feet are binary under syllabic or moraic analysis (McCarthy \& Prince, 1993a).

SYLLABLE-INTEGRITY: The contents of a syllable may not be divided between two feet (Prince, 1976).

For clarity, the related constraints are divided into subcategories. Then, the constraints of one subcategory will be discussed before we proceed into the other subcategory; this gradually builds up our hierarchy as we proceed from one constraint to another. Head categories are taken from Al-Mohanna (2004) and Al-Dweikat (2015):

Minimal requirements: Lx $\approx$ Pr, SYLLABLE-INTEGRITY 
Boundedness: PARSE- $\sigma$, FTBIN

Headedness: TROCHAIC, IAMBIC, ${ }^{*} \sigma_{(\mu)}$, MAIN-RIGHT, MAIN-LEFT

Weight-sensitivity: WSP

Directionality: ALL-FEET-RIGHT, ALL-FEET-LEFT

Extrametricality: NONFINAL, NONINITIAL

\subsection{Analysis}

\subsubsection{Minimal Requirements}

\subsubsection{Lx $\approx \operatorname{Pr}$}

The culminative property of stress observed by Liberman and Prince (1977), Hayes (1995), and Kager (2007) demands that every word must have prosody. In OT terms, this requirement is translated into $\mathrm{Lx} \approx \mathrm{Pr}$, which requires that every lexical word consists of a prosodic word, i.e., it has at least one stressed syllable. To set out the above, consider the prosodic hierarchy drawn from Selkirk (1980), McCarthy and Prince (1986), and Itô (1988) that demonstrates its descending components together, as presented below:

$$
\mid \begin{array}{ll}
\text { PrWd } & \text { prosodic word } \\
\mathrm{Ft} & \text { foot } \\
\sigma & \text { syllable } \\
\mu & \text { mora }
\end{array}
$$

This hierarchy describes, in terms of stress, that every prosodic word must have a stressed foot as its head. This foot in turn must have a stressed syllable as its head syllable, which in turn must have a mora.

Since every lexical word must be uttered with prominence, $\mathrm{Lx} \approx \operatorname{Pr}$ is undominated in Arabic; hence, we anticipate its ranking at the top of the constraint-relation hierarchy. Consider the following table that evaluates the candidate forms of /maz.ri.Sih/ (brackets "( )" indicate footing):

Table 3. $\mathrm{Lx} \approx \operatorname{Pr}$

\begin{tabular}{lll}
\hline \multicolumn{2}{l}{ maz.ri.Sih/ } & $\mathrm{Lx} \approx \operatorname{Pr}$ \\
\hline a. & {$[(\mathbf{m a z}) .($ ri) $)$.Sih $]$} & \\
b. & {$[(\mathbf{m a z})$. ri.Sih $]$} & \\
c. & {$[$ maz.ri.Sih $]$} & $! *$ \\
\hline
\end{tabular}

On one hand, candidates ' $a$ ' and ' $b$ ' both satisfy $L x \approx \operatorname{Pr}$ as they have at least one parsed syllable. On the other hand, violation of $\mathrm{Lx} \approx \operatorname{Pr}$ by candidate ' $c$ ' is not tolerated since it renders the whole word extraprosodic, i.e., with no stress. Thus, we propose that $\mathrm{Lx} \approx \operatorname{Pr}$ is lodged in the highest-ranking stratum which represents undominated constraints:

\section{Stratum 1: $\mathrm{Lx} \approx \operatorname{Pr}$}

\subsubsection{SYLLABLE-INTEGRITY}

This principle that guarantees the unsegmentability of the syllable was first introduced in an earlier work of metrical theory by Prince (1976) before being adopted by Prince and Smolensky (2004), Hayes (1995), and Blevins (1995). Under this prediction, it is essential that, for instance, the first component of a heavy syllable cannot belong to one foot and the second component belongs to the next foot. In QA, as well as most other Arabic dialects, such constraint is of extreme importance to foot construction. Consider the following table:

\section{Table 4. SYLLABLE-INTEGRITY}

\begin{tabular}{lll}
\hline \multicolumn{2}{l}{ mak.tib.tik/ } & SYLLABLE-INTEGRITY \\
\hline a. & {$[$ (mak).(tib).tik $]$} & \\
b. & {$[$ (mak.t)ib.tik $]$} & $!^{*}$ \\
c. & {$[$ ma(k.tib).tik $]$} & $! *$ \\
\hline
\end{tabular}


Candidates ' $b$ ' and ' $c$ ' forfeit optimality since they incur a serious violation to SYLLABLE-INTEGRITY. Such violation becomes also disastrous to foot formation as foot boundaries must coincide with syllable boundaries. Thus, we tentatively assume that SYLLABLE-INTEGRITY is undominated, and therefore, is housed in the undominated stratum:

Stratum 1: Lx $\approx$ Pr, SYLLABLE-INTEGRITY

\subsubsection{Boundedness}

"PARSE" constraints were first introduced by McCarthy and Prince (1993a) who demonstrated that when a given element is parsed, it is dominated by an appropriate node in the prosodic tree. Our attention is confined to the constraint that enforces the parsing of syllables into feet, i.e., PARSE- $\sigma$. Moreover, the focus will be on foot binarity as an essential foot form in bounded systems, represented by FTBIN.

\subsubsection{PARSE- $\sigma$}

PARSE- $\sigma$ requires every syllable in PrWd to be part of a foot. That is, if this constraint is undominated, all underlying syllables of the PrWd would be exhaustively parsed into feet. Consider how PARSE- $\sigma$ evaluates the candidate outputs for $/ \mathrm{mis}$.taS.mal/ in the following table:

Table 5. PARSE- $\sigma$

\begin{tabular}{lll}
\hline \multicolumn{2}{l}{ mis.taS.mal/ } & PARSE- $\sigma$ \\
\hline a. & {$[(\mathrm{mis}) .(\mathrm{taS}) .(\mathrm{mal})]$} & \\
b. & {$[(\mathrm{mis}) .(\mathrm{ta}) \cdot \mathrm{mal}]$} & $*$ \\
c. & {$[\mathrm{mis} .(\mathrm{taS}) \cdot \mathrm{mal}]$} & $* *$ \\
d. & {$[$ mis.taS.mal $]$} & $! * * *$ \\
\hline
\end{tabular}

Note that the number of violations for candidate ' $\mathrm{d}$ ' becomes fatal since it renders the entire word structure unparsed, which entails that the word has no prosody at all, thus also incurring a serious violation of $L x \approx \operatorname{Pr}$. Note also that we do not assign the pointing hand (that signals optimality) to candidate 'a' because this output is the potential rather than the actual surface form, as we will see, PARSE- $\sigma$ must be dominated by NONFINAL to disallow the parsing of final non-superheavy syllables.

\subsubsection{FOOT BINARITY (FTBIN)}

Feet are binary under syllabic or moraic analysis (McCarthy \& Prince, 1993a).

Prince (1980), Prince and Smolensky (2004), Hayes (1980), McCarthy and Prince (1986, 1990, 1993a, 1993 b), and others highlighted that an unmarked foot structure represents a binary foot, thus, in metrical phonology, feet are strictly and maximally branched binarily. Under this restriction, the minimal foot consists of two syllables when FTBIN is subjected to syllabic analysis or two moras under moraic analysis. Therefore, for our hierarchy to yield a correct stress pattern, it is crucially important that we decide whether QA feet are constructed over syllables or moras.

Assuming, first, that feet are constructed over syllables in an undiscriminated weight (see foot inventory in Hayes (1995)), and given that feet have initial prominence, i.e., trochaic, this syllabic trochee can successfully account for the stress in tri-syllabic words with light penultimate (Angled brackets " $<>$ " indicate extrametricality of the final syllable:
a. $\quad[($ mak.ti $) .<$ bih $>]$
b. $\quad[($ maz.ri $) .<$ ih $>]$
c. $\quad\left[\left(\operatorname{man} . \mathrm{t}^{\mathrm{f}} \mathrm{i}\right) \cdot<\right.$ gih $\left.>\right]$

However, the complication arises in tri-syllabic words with heavy penultimate where stress pattern cannot be accounted for; in other words, the trochaic rhythmic type in this word structure does not apply:
a. $*\left[\left(t^{\mathrm{f} a} \cdot \mathbf{l a S}\right),<\right.$ na $\left.>\right]$
b. $\quad *\left[\left(\right.\right.$ ma.hat $\left.\left.t^{\mathrm{s}}\right),<\mathrm{t}^{\mathrm{s}} \mathrm{ih}>\right]$
c. $*[($ mis.taS $),<$ mal $>]$ 
These examples show that binary feet are right-headed, which implies that syllabic trochees are not applicable in QA feet.

In contrast, when feet are interpreted under moraic analysis, i.e., constructed over one heavy syllable (CVC, CVV), or two successive light syllables (CVCV), we can account for stress in both previous sets of words:

Tri-syllabic words with light penultimate:
a. $\quad[(\mathbf{m a k})$.ti. $<$ bih $>]$
b. $\quad[(\operatorname{maz}) \cdot$.ri. $<$ 个ih $>]$
c. $\left[(\operatorname{man}) \cdot \mathrm{t}^{\mathrm{s}} \mathrm{i} .<\mathrm{gih}>\right]$

Here, since the first heavy syllable is biomoraic, it forms a foot by itself, while the second monomoraic syllable is left unparsed to satisfy FTBIN since there is no other light syllable to pair with. Note that if the monomoraic syllable is parsed into monomoraic foot, it would receive stress due to MAIN-RIGHT (subsection 4.3.3.1). Consequently, stress appropriately resides on the antepenultimate.

Tri-syllabic words with light penultimate:
a. $\quad\left[t^{\mathrm{t} a} .(\mathbf{l a S}) .<\right.$ na $\left.>\right]$
b. $\left[\mathrm{ma} .\left(\right.\right.$ hat $\left.\left.^{\mathrm{s}}\right),<^{\mathrm{t}} \mathrm{ih}>\right]$
c. $[(\mathrm{mis}) .(\mathrm{taS}) .<\mathrm{mal}>]$

The same parsing process is undertaken here where heavy syllables form feet independently, while light syllables are left unparsed. Therefore, stress correctly falls on the penult.

The previous examples provide evidence that footing in QA is mora based, where moraic trochees are a plausible interpretation of QA feet rhythmic type as a quantity-sensitive language. Consequently, we substitute the general constraint, FTBIN, into a more specific one: FTBIN- $\mu$ :

FTBIN- $\mu$ :

Feet are binary under moraic analysis.

Nonetheless, we find that a considerable number of QA word structures cannot be exhaustively parsed into binary feet. The following word structures, for instance, inescapably have left-over monomoraic syllables (in italics) which cannot be paired with other syllables to form binary feet:
a. $\quad[$ d d $a .($ rat $) .<$ na $>]$
b. $\quad[$ bga.(rat). $<$ hum $>]$
c. $\quad[$ ? $a$. (Yal). $<\lim >]$
d. $\left[(\mathrm{ma}:) . s^{\varsigma_{i}<}<\mathrm{tik}>\right]$

The question that should be addressed now is: Is there any possibility that light syllables can be parsed into a monomoraic foot? Consider the following words:
a. $\quad[(\mathbf{h i}) .<$ bir $>]$
b. $[(\mathbf{m a}),<\mathrm{lik}>]$
c. $[($ ga $) .<$ lam $>]$

These bisyllabic words are composed of an initial monomoraic syllable plus a bimoraic syllable. According to FTBIN- $\mu$, this final bimoraic syllable should be parsed into feet, and therefore host the main stress, while the initial monomoraic syllable is left unparsed. However, due to NONFINAL that requires that final syllables are left unparsed, this final syllable is not footed. This final syllable, thus, reflects conflicting demands between NONFINAL and FTBIN- $\mu$ which can be resolved by demoting FTBIN- $\mu$ lower than NONFINAL to prevent the stress from falling on the final syllable: 
Table 6. NONFINAL >> FTBIN- $\mu$

\begin{tabular}{lll}
\hline$/$ hi.bir/ & NONFINAL & FTBIN- $\mu$ \\
\hline a. $\quad[$ (hi) $)<$ bir $>]$ & & $*$ \\
b. $\quad[$ hi.(bir) $]$ & $!^{*}$ & \\
\hline
\end{tabular}

Table 6 demonstrates that this suggested ranking can successfully yield the correct stress pattern. Note that the optimal candidate violates FTBIN- $\mu$ as it has a parsed monomoraic foot, which is not a preferable foot type. The question that promptly arises here is: Can this monomoraic syllable be also unfooted to satisfy FTBIN- $\mu$ ? In fact, doing so would render the whole word unparsed, therefore, incurring a serious violation to the undominated constraint: $L x \approx \operatorname{Pr}$. Thus, we run out of options, since it is indispensable to parse the monomoraic syllable to be the head of the PrWd to satisfy $L x \approx \operatorname{Pr}$.

Based on the above-stated argument, several ranking relations can be established: First that NONFINAL dominates FTBIN- $\mu$. Thus, we have achieved the following ranking:

Ranking 1: NONFINAL >> FTBIN- $\mu$

In addition, $\mathrm{Lx} \approx \operatorname{Pr}$ dominates FTBIN $-\mu$. Thus:

Ranking 2: $\mathrm{Lx} \approx \operatorname{Pr}>>$ FTBIN $-\mu$

In addition, we have seen that when $\mathrm{Lx} \approx \operatorname{Pr}$ is at stake, $\mathrm{FTBIN}-\mu$ is violated rather than NONFINAL, therefore we tentatively assume that NONFINAL is in the same stratum of $L x \approx \operatorname{Pr}$, and hence, our initial hierarchy would look like this:

Hierarchy 1: Lx $\approx$ Pr, SYLLABLE-INTEGRITY, NONFINAL $>>$ FTBIN- $\mu$

Table 7 demonstrates the interaction of the constraints: $\mathrm{Lx} \approx \operatorname{Pr}$, NONFINAL, and FTBIN- $\mu$ in evaluating the candidate outputs for /hi.bir/:

Table 7. Lx $\approx \operatorname{Pr}>>$ NONFINAL $>>$ FTBIN $-\mu$

\begin{tabular}{|c|c|c|c|}
\hline /hi.bir/ & $\mathrm{Lx} \approx \operatorname{Pr}$ & NONFINAL & FTBIN- $\mu$ \\
\hline $\begin{array}{ll}\text { a. } & {[\text { hi. }<\text { bir }>]}\end{array}$ & $!^{*}$ & & \\
\hline b. $\quad[(\mathbf{h i}) .<$ bir $>]$ & & & $*$ \\
\hline c. $\quad[$ hi.(bir) $]$ & & $!^{*}$ & \\
\hline d. $\quad[($ hi).(bir) $]$ & & $!^{*}$ & $*$ \\
\hline
\end{tabular}

The question that promptly arises now is: Since parsing monomoraic feet is enforced in disyllabic words with a final non-superheavy syllable, does this indicate that PARSE- $\sigma$ dominates FTBIN- $\mu$ ? Assuming this ranking, consider Table 8 that demonstrates the optimal parse for /mak.ti.bih/:

Table 8. PARSE- $\sigma>>$ FTBIN- $\mu$

\begin{tabular}{llll}
\hline \multicolumn{2}{l}{ mak.ti.bih/ } & PARSE- $\sigma$ & FTBIN- $\mu$ \\
\hline a. & {$[($ mak $) .(\mathbf{t i}),<$ bih $>]$} & $*$ & $*$ \\
b. & {$[($ mak $) . t$ ti. $<$ bih $>]$} & $* *$ & \\
c. & {$[$ mak. $(\mathbf{t i}) .<$ bih $>]$} & $* *$ & $*$ \\
\hline
\end{tabular}

Candidate 'a' appears to be the optimal output since it incurs the least number of violations to PARSE- $\sigma$. However, this parse is, in fact, problematic: parsing the monomoraic foot (ti) would make this foot the host for the main stress due to the constraint MAIN-RIGHT that requires that the head foot to be the right-most foot (Subsection 4.3.3.1.). Therefore, since the actual surface form: ' $\mathrm{b}$ ', is not optimized by this suggested ranking, let us now assume the reverse ranking: FTBIN- $\mu>>$ PARSE- $\sigma$ : 
Table 9. FTBIN- $\mu$ >> PARSE- $\sigma$

\begin{tabular}{llll}
\hline /mak.ti.bih $/$ & FTBIN $-\mu$ & PARSE- $\sigma$ \\
\hline a. & {$[(\mathrm{mak}) .(\mathbf{t i}) .<\mathrm{bih}>]$} & $*$ & $*$ \\
b. $\quad[(\mathbf{m a k}) . \mathrm{ti} .<\mathrm{bih}>]$ & & $* *$ \\
c. $\quad[$ mak.(ti). $<$ bih $>]$ & $*$ & $* *$ \\
\hline
\end{tabular}

Table 9 shows that satisfying FTBIN- $\mu$ yields to optimize candidate ' $b$ ' with the correct stress pattern. Therefore, this can be taken as evidence that the ranking FTBIN- $\mu$ >> PARSE- $\sigma$ is the appropriate ranking, for nothing can be more harmonic. At this point, we have established the third ranking:

Ranking 3: FTBIN- $\mu$ > PARSE- $\sigma$

And by transitivity, we proceed in building our hierarchy that represents PARSE- $\sigma$ as the lowest, most violable constraint:

Hierarchy 2: Lx $\approx$ Pr, SYLLABLE-INTEGRITY, NONFINAL $>>$ FTBIN $-\mu>$ PARSE- $\sigma$

\subsubsection{Headedness}

\subsubsection{MAIN-RIGHT, MAIN-LEFT}

These "EDGEMOST" constraints require that the head prosodic foot is the one at the word edge. The unmarked edge-most position of the head foot is the right edge (Prince \& Smolensky, 2004, p. 34). Hence, we anticipate the dominance of MAIN-RIGHT over MAIN-LEFT in QA:

Table 10. MAIN-RIGHT $>>$ MAIN-LEFT

\begin{tabular}{llll}
\hline mak.tib.tik/ & MAIN-RIGHT & MAIN-LEFT \\
\hline a. $\quad[(\mathbf{m a k}) .(\mathrm{tib})<\mathrm{tik}>]$ & $!^{*}$ & \\
b. $\quad[(\mathrm{mak}) .(\mathrm{tib})<\mathrm{tik}>]$ & & $*$ \\
\hline
\end{tabular}

Candidate ' $\mathrm{b}$ ' is the optimal output since its head foot is situated at the right-most edge, and since stress position in this optimal output is identical to stress position in the actual surface form, it is confirmed then, that MAIN-RIGHT dominates MAIN-LEFT:

\section{Ranking 4: MAIN-RIGHT >> MAIN-LEFT}

It also appears from Table 10 that NONFINAL dominates MAIN-RIGHT, in the sense that the requirement to have the final syllable unparsed takes priority over the requirement to assign stress on the right-most edge:

Table 11. NONFINAL $>>$ MAIN-RIGHT

\begin{tabular}{|c|c|c|}
\hline /mak.tib.tik/ & NONFINAL & MAIN-RIGHT \\
\hline $\begin{array}{ll}\text { a. } & {[(\mathrm{mak}) .(\mathrm{tib}) .(\mathrm{tik})]}\end{array}$ & !* & \\
\hline$[(\mathrm{mak}) .(\mathrm{tib}) .<\mathrm{tik}>]$ & & $*$ \\
\hline c. $\quad[(\mathbf{m a k}) . \mathrm{tib} .<\mathrm{tik}>]$ & & ** \\
\hline
\end{tabular}

Thus, our established ranking is asserted:

Ranking 5: NONFINAL >> MAIN-RIGHT

In addition, one more ranking relation needs to be determined. Consider the Table 12 that evaluates the candidate output for/maz.ri.Sih/:

Table 12. NONFINAL $>>$ MAIN-RIGHT $>>$ FTBIN $-\mu$

\begin{tabular}{|c|c|c|c|}
\hline /maz.ri.Gih/ & NONFINAL & MAIN-RIGHT & FTBIN $-\mu$ \\
\hline $\begin{array}{ll}\text { a. } & {[(\mathrm{maz}) .(\mathrm{ri}) .<\mathrm{Sih}>]}\end{array}$ & & $*$ & $*$ \\
\hline b. $\quad[(\mathrm{maz}) \cdot \mathrm{ri} .<\mathrm{Sih}>]$ & & $* *$ & \\
\hline
\end{tabular}

Table 12 represents the assumed ranking of MAIN-RIGHT over FTBIN- $\mu$. With this ranking in place, the optimal output would be 'a' since it incurs the least number of violations to MAIN-RIGHT. However, this 
potential output does not correspond to the actual surface form: ' $b$ ' in Table 12. Thus, to optimize the desired output, we consider the reverse ranking below:

Table 13. NONFINAL $>>$ FTBIN- $\mu>>$ MAIN-RIGHT

\begin{tabular}{|c|c|c|c|}
\hline /maz.ri.Yih/ & NONFINAL & FTBIN- $\mu$ & MAIN-RIGHT \\
\hline $\begin{array}{ll}\text { a. } & {[(\mathrm{maz}) .(\mathbf{r i}) .<\mathrm{Gih}>]}\end{array}$ & & $*$ & $*$ \\
\hline b. $\quad[(\mathbf{m a z}) . r i .<$ iih $>]$ & & & $* *$ \\
\hline
\end{tabular}

Under this ranking, FTBIN- $\mu$ remains intact in candidate ' $b$ '. Even though two violations to MAIN-RIGHT are incurred, candidate ' $b$ ' is the optimal output. Thus, we derive the following ranking:

Ranking 6: FTBIN- $\mu$ >> MAIN-RIGHT

With these rankings in hand, MAIN-RIGHT is set directly one level lower than FTBIN- $\mu$ in our hierarchy:

Hierarchy 3: Lx $\approx$ Pr, SYLLABLE-INTEGRITY, NONFINAL $>$ FTBIN- $\mu>>$ MAIN-RIGHT, PARSE- $\sigma>>$ MAIN-LEFT

\subsubsection{2* $\sigma_{(\mu)}$}

Conforming to the views of McCarthy (1979), Hayes (1995), and Prince (1980) that parsing monomoraic syllables into degenerate feet is not preferable in most languages, this constraint reflects the universal tendency for light syllables to be unstressed. To this end, monomoraic syllables which cannot be paired with other syllables to form binary feet should not be involved in the prosodic components of a given prosodic word, therefore, they are not parsed. The ban on parsing monomoraic syllables has been already achieved by the dominance of FTBIN- $\mu$ over PARSE- $\sigma$ (see Table 9), since if the penultimate in a CVC.CV.CVC structure is parsed, it would then receive stress due to MAIN-RIGHT.

Nonetheless, although it has been stipulated in (Section 4.3.2.2.) that the unmarked foot structure is a binary foot, it is inevitable, in some cases, to parse monomoraic syllables to satisfy the undominated constraints $\mathrm{Lx} \approx \operatorname{Pr}$. It was observed in the previous section that bi-syllabic structures with non-final superheavy syllables like $[($ ga) $.<\mathrm{lam}>]$ have initial stress as a result of the interaction among NONFINAL, $\mathrm{Lx} \approx \operatorname{Pr}$ and FTBIN- $\mu$. Therefore, since the initial monomoraic syllable receives stress, ${ }^{*} \sigma_{(\mu)}$ is violated. Therefore, we can deduce that $\operatorname{Lx} \approx \operatorname{Pr}$ dominates ${ }^{*} \sigma_{(\mu)}$ :

Ranking 7: $\mathrm{Lx} \approx \operatorname{Pr}>>* \sigma_{(\mu)}$

It is also obvious that ${ }^{*} \sigma_{(\mu)}$ and PARSE- $\sigma$ impose conflicting demands: while ${ }^{*} \sigma_{(\mu)}$ militates against stressing monomoraic feet, PARSE- $\sigma$ requires that every syllable is parsed regardless of its weight. Anticipating the dominance of ${ }^{*} \sigma_{(\mu)}$ over PARSE- $\sigma$, consider Table 14 below (in the absence of the effect of FTBIN- $\mu$ ):

Table 14. ${ }^{*} \sigma_{(\mu)}>$ PARSE- $\sigma$

\begin{tabular}{|c|c|c|}
\hline /ma:.ssi.tik/ & ${ }^{*} \sigma_{(\mu)}$ & PARSE- $\sigma$ \\
\hline a. $\quad\left[(\mathrm{ma}:) .\left(\mathbf{s}^{\mathrm{s}} \mathbf{i}\right) .<\mathrm{tik}>\right]$ & * & $*$ \\
\hline b. $\quad\left[(\mathrm{ma}:) . \mathrm{s}^{\mathrm{S}} \mathrm{i} .<\mathrm{tik}>\right]$ & & ** \\
\hline
\end{tabular}

Table 14 shows that this ranking yields the correct optimal output: ' $b$ '. In this way, we can establish the following ranking:

Ranking 8: ${ }^{*} \sigma_{(\mu)}>>$ PARSE- $\sigma$

Therefore, since ${ }^{*} \sigma_{(\mu)}$ imposes the same requirement for FTBIN- $\mu$, where monomoraic feet are not allowed, it suffices to use FTBIN- $\mu$ in our domination relation hierarchy.

\subsubsection{TROCHAIC, IAMBIC}

These constraints determine feet rhythmic type, i.e., whether feet have initial prominence (TROCHAIC) or final prominence (IAMBIC). Given that QA feet as a quantity-sensitive language are interpreted under moraic analysis, we anticipate that foot type in QA is TROCHAIC. Therefore, moraic trochees are constructed over one heavy syllable (CVC) or two light syllables (CVCV). Nonetheless, QA, as well as other NA sub-dialects, does not allow the successiveness of two or more light syllables (Alqahtani, 2014). Thus, to find evidence for the trochaic nature of QA feet, we noticed how QA speakers pronounce some word structures in SA, a language with 
a much richer set of canonical patterns, allowing very long strings of light syllables (McCarthy, 1979). Such a method was also adopted by Mitchell (1960) and Hayes (1995) who noticed that Cairene speakers, in their pronunciation of stress in SA words, use rhythmical prominence derived from their native language. Initially, we investigated CV.CV.CVC structures, which are phonologically borrowed from SA:

Tri-syllabic words:
a. $\quad\left[(\mathbf{s a} .1 \mathrm{la}) .<\mathrm{t}^{\mathrm{f}} \mathrm{ah}>\right]$
b. $\quad[($ ma.li). $<\mathrm{kah}>]$
c. [(ha.la). $<$ qah $>]$

As expected, it appears that the solo foot of this set is left-headed. Furthermore, consider how QA speakers assign prominence in the following SA polysyllabic words:
a. $\quad[($ (in). $.($ ka $\cdot s a) .<\mathrm{ra}>]$
b. [(wa:).(qi.fa). $<$ tun $>]$
c. $\quad[(\mathrm{mak}) .($ ta.ba) $)<\mathrm{tuh}>]$
d. $\quad[($ a.ja).(ra.tu). $<$ na $>]$
e. $\quad[($ ma.li). $(k a \cdot t u) .<$ na $>]$
f. $\quad[($ ?al).(mam).(la.ka). $<\mathrm{ti}>]$

Here, prominence has landed on the antepenultimate syllable. It is apparent that the head foot in this set is the right-most foot, and this foot is left-headed. Therefore, these feet are doubtlessly trochaic. Thus, we can consider that the rhythmic foot type in QA is a moraic trochee:

\section{Ranking 9: TROCHAIC >> IAMBIC}

Since no constraint appears to be in conflict with TROCHAIC, it is set at the highest-ranking stratum. Thus, our hierarchy would look like this:

Hierarchy 4: Lx $\approx$ Pr, SYLLABLE-INTEGRITY, NONFINAL, TROCHAIC $>$ FTBIN- $\mu>>$ MAIN-RIGHT, PARSE- $\sigma$

\subsubsection{FAITH-PK}

At this point, we need to consider how the first exceptional case to NASRs (Subsection 3.1) can be accounted for in the OT framework. The word structures in (3.1) do not conform to the primary rankings we have tried to establish (Hierarchy 4): by assigning stress to the light penultimate since FTBIN $-\mu$ and ${ }^{*} \sigma_{\mu}$ are seriously violated. Therefore, another constraint must be introduced to optimize the desired output. It has been also pointed out that the stressed vowel in these underlying forms appears to preserve the stress in the surface form. Therefore, a faithfulness constraint needs to be added to the set of constraints to account for the necessity that the stressed vowel in the input must be preserved in the output. In the OT literature, Oh (1998) has proposed FAITH-PK:

\section{FAITH-PK:}

If a segment is the stress peak of the input, it is the stress peak of the output (Oh, 1998, p. 22).

It is agreed that the general tendency in QA word structures is to destress monomoraic syllables, which is expressed by FTBIN- $\mu$ and ${ }^{*} \sigma_{(\mu)}$. Nonetheless, if these constraints over-rank FAITH-PK, it would not be possible to stress light syllables in the word set in (3.1). Therefore, FAITH-PK must outrank any other constraint that requires the destressing of monomoraic syllables. Thus, FAITH-PK must dominate FTBIN- $\mu$. Table 15 lays it out:

Table 15. FAITH-PK >> FTBIN- $\mu$

\begin{tabular}{|c|c|c|}
\hline /2al.Sa.s'ir/ & FAITH-PK & FTBIN $-\mu$ \\
\hline a. $\quad\left[(\mathrm{Pal}) .(\mathbf{S a}) .<\mathrm{s}^{\mathrm{s}} \mathrm{ir}>\right]$ & & $*$ \\
\hline b. $\quad\left[(\right.$ (2al) $)$, a $<<^{S}$ ir $\left.>\right]$ & $!^{*}$ & \\
\hline
\end{tabular}


Table 15 shows that the assigned ranking yields the desired output form, which provides evidence that the violation of FTBIN- $\mu$ is tolerated. Therefore, the requirement of FAITH-PK, in short, takes priority:

\section{Ranking 10: FAITH-PK >> FTBIN- $\mu$}

FAITH-PK has no constraints to conflict with other than FTBIN- $\mu$, therefore, it is set at the first stratum in our hierarchy, just above FTBIN- $\mu$ :

Hierarchy 5: Lx $\approx$ Pr, SYLLABLE-INTEGRITY, NONFINAL, TROCHAIC, FAITH-PK $>$ FTBIN- $\mu>>$ MAIN-RIGHT, PARSE- $\sigma$

\subsubsection{Weight-Sensitivity}

In quantity-sensitive languages, heavy syllables are more likely to attract stress. In QA, this is apparent by the tendency of non-final heavy syllables to receive stress more than light syllables; this is expressed by the constraint $* \sigma_{(\mu)}$. FTBIN- $\mu$ also militates against parsing monomoraic syllables. These constraints go in tandem with WSP. Consider how stress is attracted by heavy syllables:

a. $\quad[$ ma. (каa) $)<\theta$ ih $>$ ]

b. $\quad[($ mak $)$. ti. $<$ bih $>]$

Nonetheless, WSP can be violated. For instance, in QA we find the existence of some word structures with stressed light syllables despite the existence of heavy syllables. This is due to other higher-ranked constraints that would be satisfied at the expense of violating WSP: NONFINAL, for instance, mitigates assigning stress to final heavy syllables, as shown in Table 16:

Table 16. NONFINAL >> WSP

\begin{tabular}{lll}
\hline$/$ hi.bir/ & NONFINAL & WSP \\
\hline a. $\quad[(\mathbf{h i}) .<$ bir $>]$ & & $*$ \\
b. $\quad[$ hi.(bir) $]$ & $!^{*}$ & \\
\hline
\end{tabular}

Optimal candidate 'a' sacrifices WSP to satisfy NONFINAL. Therefore, NONFINAL dominates WSP:

Ranking 11: NONFINAL $>>$ WSP

FAITH-PK is also shown to assign stress to light penultimate syllables rather than initial heavy syllables:

Table 17. FAITH-PK >> WSP

\begin{tabular}{|c|c|c|}
\hline /Ral.Sasr/ & FAITH-PK & WSP \\
\hline a. $\quad\left[(\mathrm{Pal}) .(\mathbf{C a}),<\mathrm{S}^{\mathrm{S} \text { ir }>}\right]$ & & $*$ \\
\hline 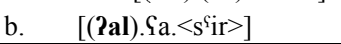 & $!^{*}$ & \\
\hline
\end{tabular}

The optimal output satisfies FAITH-PK. Therefore, FAITH-PK dominates WSP:

Ranking 12: FAITH-PK >> WSP

Thus, since WSP is dominated by NONFINAL and FAITH-PK, it is set at a lower stratum:

hierarchy 6: Lx $\approx$ Pr, SYLLABLE-INTEGRITY, NONFINAL, TROCHAIC, FAITH-PK $>>$ FTBIN- $\mu$, WSP $>>$ MAIN-RIGHT, PARSE- $\sigma$

4.3.5 Directionality

\subsubsection{ALL-FEET-RIGHT, ALL-FEET-LEFT}

The direction of parsing can best be determined by noticing how QA speakers pronounce SA words containing multiple sequences of light syllables. i.e., words following the structure CVC.CV.CV.CV. $<\mathrm{CV}>$ :

a. (mam).la.(ka.tu). $<$ na $>$ 'our kingdom'

b. (mak).ta.(ba.tu). $<\mathrm{ki}>$ 'your library'

c. (Pad).wi.(ya.tu). $<\mathrm{ka}>$ 'your medicines' 
As stress is placed on the antepenultimate syllable; the feet are, therefore, parsed binarily from right to left, since if parsing was performed the other way round, i.e., from left to right, these words would have a different stress pattern:
a. $\quad *$ (mam).(la.ka).tu. $<$ na $>$
b. $\quad *$ (mak).(ta.ba).tu. $<\mathrm{ki}>$
c. $\quad *(\mathrm{lad})$.(wi.ya).tu. $<\mathrm{ka}>$

Thus, this can be taken as evidence that ALL-FEET-RIGHT dominates ALL-FEET-LEFT. Thus, we have ranking '13':

\section{Ranking 13: ALL-FEET-RIGHT >> ALL-FEET-LEFT}

Nonetheless, note that the right-most foot in the previous word set incurs one violation to ALL-FEET-RIGHT since they do not occur at word right-most edge; this is due to the undominated constraint NONFINAL:

Table 18. NONFINAL >> ALL-FEET-RIGHT

\begin{tabular}{lll}
\hline input & NONFINAL & ALL-FEET-RIGHT \\
\hline a. & (mam).la.(ka.tu).na & $*, * * * *$ \\
b. & (mak).ta.(ba.tu).ki & $*, * * * *$ \\
c. & (Pad).wi.(ya.tu).ka & \\
\hline
\end{tabular}

It is more important then, to leave the final syllable unparsed than to align feet at the right edge. ALL-FEET-RIGHT is, therefore, made subordinate:

Ranking 14: NONFINAL >> ALL-FEET-RIGHT

Therefore ALL-FEET-RIGHT is set directly below NONFINAL in our hierarchy:

Hierarchy 7: Lx $\approx$ Pr, SYLLABLE-INTEGRITY, NONFINAL, TROCHAIC, FAITH-PK $>$ FTBIN- $\mu$, WSP, ALL-FEET-RIGHT $>>$ MAIN-RIGHT, PARSE- $\sigma$

\subsubsection{Extrametricality}

The notion of extrametricality (Liberman \& Prince, 1977) indicates that a particular prosodic constituent is designated as invisible for purposes of stress rule application. This invisibility entails that this constituent is not parsed into a foot, or in other words, it cannot form a prosodic head. In OT terms, extrametricality is translated into two constraints, namely, NONFINAL and NONINITIAL. Usually, the unparsed constituent is the one at the word's right-most edge, therefore, the unmarked phonological structure corresponds to the constraint NONFINAL:

a. $\quad[(\mathbf{2 a}),<\mathrm{kal}>]$

b. $[(\mathbf{m a k}) .<\mathrm{tab}>]$

c. $\quad[(\mathbf{m a k}) . \mathrm{ti} .<\mathrm{bih}>]$

' $a$ ' and ' $b$ ' are disyllabic words that have initial stress due to the domination of NONFINAL. On the other hand, ' $c$ ' is a tri-syllabic word with initial stress due to the interaction of NONFINAL and FTBIN- $\mu$. This implies that NONINITIAL is a constraint with a less significant effect, and therefore, is dominated by NONFINAL and FTBIN- $\mu$ :

\section{Ranking 15: NONFINAL $>$ FTBIN $-\mu>>$ NONINITIAL}

However, to the best of the researcher's knowledge, there is only one exceptional case where stress is, contrary to expectations, strictly banned from falling on the initial syllable. This case has been elaborated in (Subsection 3.2). In OT terms, we introduce here an argument for this exceptional case to NASRs and consider how NONINITIAL affects its stress pattern.

\subsubsection{NONINITIAL}

In Section (3.2) we posit that some surface forms with a CV.CV.CVC structure do exist, however, with noninitial prominence. As pointed out above, there are two underlying forms for such a structure: / $\mathbf{2 a C}$.CVC/: / $\mathbf{2 a}$. dim/ 
and /CV.CV.CVC/: / 2a.ka.lat/. It is also demonstrated that the two forms have undergone different derivation processes. This indicates that, unlike the word structures in (3.1), we cannot rely on a constraint that requires the preservation of the underlyingly assigned stress, since stress in the second underlying form is actually not preserved at the surface level. Therefore, it is important to carefully scrutinize the surface representation. What these structures actually have in common is that they are all tri-syllabic words, with a CV.CV.CVC form, a structure that is not preferable in QA. In addition, it appears that the most distinguishable particularity is that they begin with identical initial syllable: / $\mathrm{Pa}$ /, and this syllable revokes primary stress. For present purposes, we attempt to construct a formalism of this particular case by introducing a "noninitial" constraint: *[?a.:

*[?a.

Initial light syllables with $/ \mathrm{Ra} /$ structure are not stressed.

By stating such a constraint, any word structure that has an initial $/ \mathrm{Ra} /$ syllable must not be stressed. Nonetheless, this constraint will conflict with the previously stated constraints, such as FTBIN- $\mu$, and TROCHAIC. Assuming that TROCHAIC and FTBIN- $\mu$ dominate *[?a., then the Pa.CV.CVC structure must be parsed binarily, we then have the first two light syllables parsed into a foot: *(Pa.CV). $<\mathrm{CVC}>$. Consequently, due to TROCHAIC, the initial syllable must be stressed:

Table 19. TROCHAIC $>>$ FTBIN $-\mu>>*[$ ?a.

\begin{tabular}{|c|c|c|c|}
\hline /Pa.Sa.dzin/ & TROCHAIC & FTBIN- $\mu$ & $*[? a$. \\
\hline $\begin{array}{ll}\text { a. } & {[(\text { ?a.Sa }) .<\text { dgin }>]}\end{array}$ & & & $*$ \\
\hline$[($ Pa.Sa $) .<$ dzin $>]$ & * & & \\
\hline c. $\quad\left[\right.$ [a. $\left.(\mathbf{S a}) .<\mathrm{d}_{3} \mathrm{in}>\right]$ & & $*$ & \\
\hline
\end{tabular}

When *[?a. is sacrificed to satisfy both FTBIN- $\mu$, and TROCHAIC, this would yield output 'a' incorrectly as optimal. Therefore, *[?a. would rather be satisfied, and since it is already set that TROCHAIC >> FTBIN- $\mu$, it is more appropriate to violate the requirement of FTBIN- $\mu$ to avoid the serious violation of the higher-ranked TROCHAIC (the shaded cell indicates that the constraint is irrelevant):

Table 20. TROCHAIC $>>*$ ? ?a. $>>$ FTBIN $-\mu$

\begin{tabular}{|c|c|c|c|}
\hline /2a.Sa.dzin/ & TROCHAIC & $*[$ ?a. & FTBIN- $\mu$ \\
\hline a. [(2a.Sa).dzin] & & $!^{*}$ & \\
\hline b. [(Pa.Sa).dzin $]$ & $!^{*}$ & & \\
\hline c. $\quad[$ Pa.(Sa).dzin $]$ & & & * \\
\hline
\end{tabular}

Even though candidate 'a' satisfies the higher-ranked TROCHAIC, it should be factored out as this potential form does not match the actual form. Moreover, FTBIN- $\mu$ must be avoided to prevent a disastrous ending like that in candidate ' $b$ '. Candidate ' $c$ ', then, wins the competition by reaching out the desired output. Therefore, we establish the following ranking:

Ranking 16: *[?a. >> FTBIN- $\mu$

Nonetheless, the question that should be addressed now is: Does the constraint *[?a. include all forms with initial syllables of the form $/ \mathrm{Ra} /$ ? Consider the following words:
a. [?a. $\theta$ ir $]$
b. [?a.sir]
c. [?a.mir]

The major difference between this set and the previous set in (3.4) is in the number of syllables, i.e., the former set consists of tri-syllabic words, while the latter set consists of bisyllabic words. If the constraint *[?a. is satisfied in this bisyllabic structure, stress would fall on the final syllable, thus violating NONFINAL. Therefore, this clash between *[?a. and NONFINAL should be resolved. Table 21 lays this out: 
Table 21. NONFINAL $>>*$ [?a.

\begin{tabular}{|c|c|c|}
\hline /Pa.sir/ & NONFINAL & $*[$ [a. \\
\hline $\begin{array}{lll}a- & {[(2 a) \cdot s i r}\end{array}$ & & $*$ \\
\hline b- $\quad[$ ?a.(sir) $]$ & $*$ & \\
\hline
\end{tabular}

The optimal form shows that $*[$ ?a. is demoted to satisfy NONFINAL. Thus, when NONFINAL is at stake, $*[$ ?a. is violated:

Ranking 17: NONFINAL $>>*$ ?

Given that NONFINAL $>>*[$ ?a. $>>$ FTBIN $-\mu, *[$ ?a. is set in a stratum below NONFINAL and above FTBIN- $\mu$ :

Hierarchy 8: Lx $\approx$ Pr, SYLLABLE-INTEGRITY, NONFINAL, TROCHAIC, FAITH-PK $>>*$ ? ?a. $>>$ FTBIN- $\mu$, WSP $>>$ ALL-FEET-RIGHT, MAIN-RIGHT, PARSE- $\sigma$

\subsubsection{NONFINAL}

Due to the influential rule of NONFINAL in most QA structures, it has been considerably integrated into the above-mentioned domination relations. In addition, NONFINAL, until now, has been set at the same stratum as Lx $\approx \operatorname{Pr}$, SYLLABLE-INTEGRITY, TROCHAIC, and FAITH-PK. Given that this type of extrametrical constituent is language-specific (Hayes, 1995), it is crucially important to decide whether nonfinality is interpreted under syllabic or consonantal analysis. For exemplification, consonant extrametricality is present in the works of McCarthy and Prince (1990, 1993b), Hayman (1985), Steriade (1982), and Ito (1988), while syllable extrametricality is adopted by Liberman and Prince (1977), Kager (2004, 1995), Kenstowicz (1994), Buell and Steriade (1996), and McCarthy (2002).

For Arabic, the research on syllabification has agreed on the extrametricality of the final $\mathrm{C}$, where the final consonant is always moraless under the constraint *FINAL-C- $\mu$. To mention some, I refer the reader to Hayes' (1995) analysis of Cairene moraic trochees, McCarthy (1979), Al Motairi (2015), and Alqahtani, (2014). Notwithstanding this agreement, I argue here that consonant extrametricality, even though it is applicable in some forms, cannot be applied to all QA forms. We begin our argument by stating sets of structures that can be applied to both consonant and syllable extrametricality:

Bisyllabic words: (syllable extrametricality)
a. (Sa). $<\mathrm{t}^{\mathrm{f}} \mathrm{a}>$
b. (fa). $<t^{\mathrm{f}} a \mathrm{t}>$
c. $\left(\mathbf{r a t}^{\mathrm{t}}\right) \cdot<\mathrm{t}^{\mathrm{f}} \mathrm{at}>$

Bisyllabic words: (consonant extrametricality)

d. (Ga.t $\left.t^{\mathrm{f}} \mathbf{a}\right)$

e. $\left(\right.$ ( $\left.a . t^{\dagger} a\right) .<t>$

f. $\quad\left(\boldsymbol{s} a t^{\mathrm{f}}\right) \cdot \mathrm{t}^{\mathrm{f}} \mathrm{a}<\mathrm{t}>$

These structures can be applied to both types of extrametricality: In the case of syllable extrametricality, 'a-c' have initial stress due to $L x \approx \operatorname{Pr}$. In the case of consonant extrametricality, 'd-e' have initial stress since they can form a trochaic foot. ' $\mathrm{f}$ ' has initial stress due to FTBIN- $\mu$.

Tri-syllabic words: (syllable extrametricality)
a. $\quad$ Pa.(Ya). $<$ rif $>$
b. $\quad$ Pa.(Yal). $<\lim >$
c. (mak).(tib).<tik>

Tri-syllabic words: (consonant extrametricality)

d. $\quad$ Pa.(Ya.ri) $<\mathrm{f}>$

e. $\quad$ Pa.(Yal).li $<\mathrm{m}>$

f. (mak).(tib).ti $<$ k $>$ 
These structures, too, can be applied well to both types of extrametricality: i.e., in syllable extrametricality, 'a' has penultimate stress due to *[?a.. ' $b-c$ ' have penultimate stress due to FTBIN- $\mu$ in ' $b$ ' and due to MAIN-RIGHT in ' $c$ '. In contrast, when extrametricality is present at the consonant level, ' $d$ ' has an opportunity to form a trochaic foot that is parsed from right to left due to ALL-FEET-RIGHT. Then the foot, of course, is left-headed, due to TROCHAIC. 'e' has penultimate stress due to FTBIN- $\mu$. Finally, ' $\mathrm{f}$ ' has penultimate stress due to FTBIN- $\mu$ and MAIN-RIGHT.

The previous sets of words succeeded in accounting for stress when extrametricality is interpreted under both consonantal or syllabic analyses. However, when extrametricality is interpreted under consonantal level, the constraint-relation hierarchy would fail to account for stress patterns in the tri-syllabic structure: CVC.CV.CVC. Consider these examples:
a. $\quad *$ (mak).(ti.bi) $<\mathrm{h}>$
b. $\quad *(\min ) .\left(\right.$ gi..$\left.^{\mathrm{f}} \mathrm{i}\right)<\mathrm{Q}>$
c. $\quad *$ (mis).(fi.hi) $<\mathrm{l}>$

These words are supposed to have antepenultimate stress. However, assuming that the final consonant is extrametrical, the last two syllables consequently form a trochaic foot, and, due to MAIN-RIGHT this right-most foot becomes the head foot resulting in penultimate stress: ${ }^{*}(\mathrm{CVC}) .(\mathrm{CV} . \mathrm{CV})<\mathrm{C}>$.

In contrast, when such structures have syllable extrametricality, i.e., (CVC).CV. $<\mathrm{CVC}>$ the initial syllable would successfully receive the stress due to FTBIN- $\mu$ :

$\begin{array}{ll}\text { a. } & {[(\text { mak }) . t i .<\text { bih }>]} \\ \text { b. } & {\left[(\text { min }) . \text { gi. }<\mathrm{t}^{\mathrm{f} i \mathrm{C}>}\right]} \\ \text { c. } & {[(\text { mis }) . \text { fi. }<\text { hil }>]}\end{array}$

The argument presented above provides evidence that NONFINAL is applied at the syllable level rather than the consonant level. Nonetheless, under this assumption, stressed final superheavy syllables appear to contradict this argument, since if NONFINAL is undominated, final superheavies would never be able to attract stress:

Table 22. NONFINAL

\begin{tabular}{lcl}
\hline \multicolumn{1}{l}{ dar.rast $/$} & NONFINAL \\
\hline a. & {$[($ dar$) .<$ rast $>]$} & \\
b. & {$[($ dar).(rast) $]$} & $! *$ \\
\hline
\end{tabular}

In terms of nonfinality, previous work has attempted to find a way to distinguish between parsing final superheavy and non-superheavy syllables in terms of constraint relativization: in Al-Jarrah (2002), for example, NONFINAL is relativized into NONFINAL $\left(\sigma_{\mu \mu}\right)$, which bans stressing syllables of two mora or less, and $\operatorname{NONFINAL}\left(\sigma_{\mu \mu \mu}\right)$, which bans stressing syllables of three moras. By this relativization, the following domination relation is defined:

$\operatorname{NONFINAL}\left(\sigma_{\mu \mu}\right)>>$ PARSE $\sigma>\operatorname{NONFINAL}\left(\sigma_{\mu \mu \mu}\right)$

On the one hand, this means that since $\operatorname{NONFINAL}\left(\sigma_{\mu \mu}\right)$ dominates PARSE- $\sigma$, any final non-superheavy syllable is not parsed. On the other hand, since PARSE- $\sigma$ dominates $\operatorname{NONFINAL}\left(\sigma_{\mu \mu \mu}\right)$, it is indicated that the ban against stressing final trimoraic syllables is violated, so that final superheavy syllables are parsed.

Another attempt by AlDweikat (2013) who, instead of relativizing NONFINAL, relativized PARSE- $\sigma$ into undominated PARSE- $\sigma_{\mu \mu \mu}$ that forces parsing any trimoraic syllable at any word position, and a lower-ranked PARSE- $\sigma_{\mu(\mu)}$ which is dominated by NONFINAL to ban stressing final non-superheavy syllables. Thus, the following domination relation is established:

PARSE- $\sigma_{\mu \mu \mu}>>$ NONFINAL $>>$ PARSE- $\sigma_{\mu(\mu)}$

The question that promptly arises here is do we have to relativize NONFINAL as in Al-Jarrah (2002), so that the violable NONFINAL $\left(\sigma_{\mu \mu \mu}\right)$ would allow final stress to superheavies - or do we have to relativize PARSE- $\sigma$ as in AlDweikat (2013) so that the undominated PARSE- $\sigma_{\mu \mu \mu}$ would force the parsing of any trimoraic syllable? 
To address this, one study took a different approach: Within metrical phonology, McCarthy (1979) and Hayes (1980) view a superheavy syllable as one that branches into two rhymes: a heavy syllable plus a degenerate, i.e., consisting of a single consonant. Similarly, McCarthy and Prince (1990) account for the "stem-final consonant" in superheavy syllables as an extrametrical final consonant dominated by an extrametrical 'vowel-less' final syllable. This incomplete final syllable is, therefore, moraless:

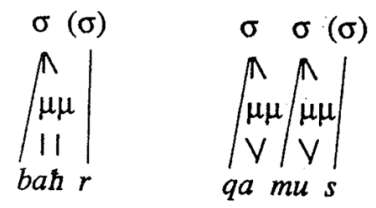

Figure 1. Final consonants in superheavy syllables

Source: McCarthy \& Prince, 1990, p. 14.

Under this analysis, Broselow (1992, p. 9) observed that: "syllables that appear to be trimoraic are actually composed of two independent syllables: a bimoraic syllable followed by a syllable dominating only a consonant". Such notion of "extrasyllabicity" of final consonant was also adopted by Hayman (1985), Ito (1988), Burzio (1994), Al-Mohanna (2004), Watson (2011), and Kiparsky (2003). It is therefore suggested that NONFINAL is applied to the final consonant as it constitutes a peripheral syllable, at the same time, depriving the left branch of the superheavy syllable of peripherality (for restrictions on extrametricality, see Hayes, 1995). Consequently, the first part of the superheavy syllable hosts the stress as the right-most foot:

Table 23. NONFINAL $>>$ MAIN-RIGHT $>>$ PARSE- $\sigma$

\begin{tabular}{|c|c|c|c|}
\hline /dar.rast/ & NONFINAL & MAIN-RIGHT & PARSE- $\sigma$ \\
\hline a. $\quad[($ dar $) .($ ras $)<t>]$ & & & $*$ \\
\hline b. $\quad[($ dar $) .($ rast $)]$ & !* & & \\
\hline c. $[($ dar $) .(\operatorname{ras})<t>]$ & & $!^{*}$ & * \\
\hline
\end{tabular}

In Table 23, candidate ' $a$ ' wins the competition since the final consonant intervenes between the right edge and the heavy syllable, thus satisfying the higher-ranked NONFINAL and MAIN-RIGHT. Table 23 demonstrates how the assumption that the final consonant in the final superheavy syllable is a peripheral element that successfully avoids the clash between NONFINAL and stressing final superheavies. At the same time, all such complicated relativization for NONFINAL and PARSE- $\sigma$ can be avoided.

Now, turning to constraint ranking, hierarchy ' 8 ' shows that NONFINAL is undominated. However, our hierarchy does not account for stress in monosyllabic words, i.e., NONFINAL as an undominated constraint would render the whole monosyllabic word extrametrical. The problem in this exhaustive "unparsing" lies in that it violates the undominated $\mathrm{L} x \approx \operatorname{Pr}$ :

Table 24. Lx $\approx \operatorname{Pr}>>$ NONFINAL

\begin{tabular}{llll}
\hline /gil/ & Lx $\approx \operatorname{Pr}$ & NONFINAL \\
\hline a. $[$ gil $]$ & $! *$ & \\
b. & {$[($ gil $)]$} & & $*$ \\
\hline
\end{tabular}

Therefore, when $\mathrm{Lx} \approx \operatorname{Pr}$ is at stake, NONFINAL is violated. This goes in tandem with the notion of "nonexhaustivity" (Hayes, 1995). It also confirms the views of Prince and Smolensky (2004) that Lx $\approx \operatorname{Pr}$ 'revokes extrametricality' when content-word monosyllables are involved. Thus, we reach the following significant ranking:

Ranking 18: $\mathrm{Lx} \approx \operatorname{Pr}>>$ NONFINAL

Given from Ranking ' 17 ' that NONFINAL dominates *[?a., NONFINAL is therefore set in a higher stratum:

Hierarchy 9: Lx $\approx$ Pr, SYLLABLE-INTEGRITY, TROCHAIC, FAITH-PK $>>$ NONFINAL $>>*[$ ?a. $>>$ FTBIN- $\mu$, WSP, ALL-FEET-RIGHT >> MAIN-RIGHT, PARSE- $\sigma$ 


\section{Conclusion}

This study aimed to employ OT to account for stress patterns in QA. As a subdialect of NA, NA stress patterns were presented, and two exceptional cases were illustrated: the first case, represented in forms like [?al.\{a.s $\mathbf{S}^{\mathrm{S} i r]}$, the analysis instantiates the significance of the finding that stress in underlying forms is preserved. The second case, represented in forms like [?a.Sa.rif], demonstrated that the initial syllables of the form [?a. in tri-syllabic words are not allowed to host stress.

After elaborating on stress patterns in QA, the constraints that are most related to QA word stress were stated, and some definitional decisions were made before proceeding to the constraint-ranking process. For instance, it was demonstrated that feet are binary under moraic rather than syllabic analysis. Also, extrametricality was interpreted at the syllabic rather than the consonantal level. Furthermore, the final superheavy syllable consists of two syllables: a biomoraic syllable plus a degenerate one, the latter, as the peripheral element is that which is deemed extrametrical. By such analysis, any relativization to NONFINAL and PARSE- $\sigma$ can be avoided.

Then, in terms of constraint interaction, constraints are ranked hierarchically one after another until the following constraint-relation hierarchy was produced:

Hierarchy 10: Lx $\approx$ Pr, SYLLABLE-INTEGRITY, TROCHAIC, FAITH-PK $>$ NONFINAL $>$ *[?a. $>>$ FTBIN- $\mu$, WSP, ALL-FEET-RIGHT $>>$ MAIN-RIGHT, PARSE- $\sigma$

\section{References}

Abboud, P. (1979). The verb in northern Najdi Arabic. Bulletin of the School of Oriental and African Studies, 42(3), 467-499. https://doi.org/10.1017/S0041977X0013575X

Al Motairi, S. (2015). An optimality-theoretic analysis of syllable structure in Qassimi Arabic (Order No. 1593801). ProQuest Dissertations \& Theses Global. (1698103976). Retrieved from https://search-proquest-com.sdl.idm.oclc.org/docview/1698103976?accountid=142908

Al-Dweikat, A. (2015). Word Stress of Najdi Arabic: An Optimality Theoretic Analysis. Doctoral dissertation, Yarmouk University. Retrieved from http://search.mandumah.com/record/721583

Al-Jarrah, R. (2002). An optimality-theoretic analysis of stress in the English of native Arabic speakers. Doctoral dissertation, Ball State University. http://faculty.yu.edu.jo/raljjara/Lists/ThesesDissertation\%20Supervision/Attachments/1/PhD_thesis[1]

Al-Jarrah, R. (2008). Cairene Arabic word stress: A constraint-based analysis. Dirasat, Human and Social Sciences, 35(3), 1-13. $\quad$ Retrieved from http://faculty.yu.edu.jo/raljjara/Lists/Published\%20Research/Attachments/3/cairene-rashed[1]

Al-Mohanna, F. (2004). Paradoxical non-finality: Stress assignment in three Arabic dialects. Retrieved from $\mathrm{http}: / /$ citeseerx.ist.psu.edu/viewdoc/download?doi=10.1.1.570.7816\&rep=rep1\&type=pdf

Al-Mozainy, H. (1981). Vowel alternations in a Bedouin Hijazi Arabic dialect: Abstractness and stress. Doctoral dissertation.

Retrieved

from https://www-proquest-com.sdl.idm.oclc.org/dissertations-theses/vowel-alternations-bedouin-hijazi-arabic-di alect/docview/303036696/se-2?accountid=142908 (Order No. 8119247)

AlAmro, M. (2015). Syllabification in Najdi Arabic: A constraint-based analysis. Arab World English Journal, 6. https://doi.org/10.2139/ssrn.2847466

AlAmro, M. (2019). Word Stress in Saudi Najdi Arabic. American International Journal of Social Science, 8(3), 30-34. https://doi.org/10.30845/aijss.v8n3p5

Alqahtani, M. (2014). Syllable structure and related processes in optimality theory: An examination of Najdi Arabic. Doctoral dissertation, Newcastle University. Retrieved from http://hdl.handle.net/10443/2757

Aquil, R. (2012). Optimality theoretic representation of stress in Cairene Arabic. Open Journal of Modern Linguistics, 02(03), 85-89. https://doi.org/10.4236/ojml.2012.23011

Blevins, J. (1995). The syllable in phonological theory. In J. Goldsmith (Ed.), The Handbook of Phonological Theory (pp. 206-244). Blackwell Publishing. Retrieved from http://www.blackwellreference.com/subscriber/book?id=g9780631201267_9780631201267

Broselow, E. (1992). Parametric variation in Arabic dialect phonology. In Perspectives on Arabic linguistics (pp. 7-46). John Benjamins. https://doi.org/10.1075/cilt.85.04bro

Btoosh, M. (2006). Constraint interactions in Jordanian Arabic phonotactics: An optimality-theoretic approach. 
Journal of Language and Linguistics, 5(2), 102-221. Retrieved from https://www.academia.edu/download/36223350/Constraints_Interactions_in_JA-_06-03

Buell, L., \& Steriade, D. (1996). A footless, constraint-based analysis of stress in Cairene Arabic. Linguistics, 195. Retrieved from http://citeseerx.ist.psu.edu/viewdoc/download?doi=10.1.1.488.3747\&rep=rep1\&type=pdf

Burzio, L. (1994). Principles of English stress. Cambridge University Press. https://doi.org/10.1017/CBO9780511519741

Chomsky, N. (1965). Aspects of the Theory of Syntax. The MIT Press. https://doi.org/10.21236/AD0616323

Chomsky, N., \& Halle, M. (1968). The Sound Pattern of English. The MIT Press.

Hayes, B. (1980). A metrical theory of stress rules. Doctoral dissertation, Massachusetts Institute of Technology. Retrieved from http://journals.linguisticsociety.org/proceedings/index.php/BLS/article/viewFile/1898/1670

Hayes, B. (1995). Metrical stress theory: Principles and case studies. University of Chicago Press.

Hyman, L. (1985). A theory of phonological weight. Foris Publications. https://doi.org/10.1515/9783110854794

Ingham, B. (1994). Najdi Arabic: Central Arabian. John Benjamins Publishing Company. https://doi.org/10.1075/loall.1

Itô, J. (1988). Syllable theory in prosodic phonology. Routledge.

Jarrah, A. (2013). Syllables and syllable structure in Arabic in the light of the optimality theory. Open Science Repository Language and Linguistics, (open-access), e70081958.

Kager, R. (1995). Metrical Stress Theory: Principles and Case Studies. Phonology, 12(3), $437-464$. https://doi.org/10.1017/S095267570000258X

Kager, R. (1999). Optimality Theory. Cambridge University Press. https://doi.org/10.1017/CBO9780511812408

Kager, R. (2007). Feet and metrical stress. In The Cambridge handbook of phonology (pp. 195-227). https://doi.org/10.1017/CBO9780511486371.010

Kenstowicz, M. (1994). Phonology in generative grammar. Blackwell.

Kiparsky, P. (2003). Syllables and moras in Arabic. In C. A. Féry \& R. van de Vijver (Eds.), The syllable in optimality theory (pp. 147-182). Cambridge University Press. https://doi.org/10.1017/CBO9780511497926.007

Liberman, M., \& Prince, A. (1977). On stress and linguistic rhythm. Linguistic Inquiry, 8(2), 249-336. Retrieved from https://www.jstor.org/stable/4177987

McCarthy, J. (1979). On stress and syllabification. Linguistic Inquiry, 10(3), 443-465. Retrieved from https://www.jstor.org/stable/4178121

McCarthy, J. (2002). A thematic guide to Optimality Theory. Cambridge University Press. https://doi.org/10.1017/CBO9780511613333

McCarthy, J., \& Prince, A. (1986). Prosodic morphology 1986. Linguistics Department Faculty Publication Series. 13. Retrieved from https://scholarworks.umass.edu/linguist_faculty_pubs/13

McCarthy, J., \& Prince, A. (1990). Prosodic morphology and templatic morphology. In Perspectives on Arabic linguistics II: papers from the second annual symposium on Arabic linguistics (p. 16). https://doi.org/10.1075/cilt.72.05mcc

McCarthy, J., \& Prince, A. (1993a). Prosodic morphology: Constraint interaction and satisfaction. Linguistics $\begin{array}{llllll}\text { Department } & \text { Faculty } & \text { Publication } & \text { Series. } & 14 . & \text { Retrieved }\end{array}$ https://scholarworks.umass.edu/linguist_faculty_pubs/14

McCarthy, J., \& Prince, A. (1993b). Generalized alignment. In Yearbook of morphology 1993 (pp. 79-153). Springer. https://doi.org/10.1007/978-94-017-3712-8_4

Mitchell, T. (1960). Prominence and syllabication in Arabic. Bulletin of the School of Oriental and African Studies, 23(2), 369-389. https://doi.org/10.1017/S0041977X00149997

Oh, E. (1998). Stress Patterns of Bedouin Hijazi Arabic: An OT Account. Kansas Working Papers in Linguistics, 23(1), 17-26. https://doi.org/10.17161/KWPL.1808.339

Prince, A. (1976). Applying stress. University of Massachusetts, Amherst. Retrieved from 
https://ruccs.rutgers.edu/images/personal-alan-prince/hold/app_str.pdf

Prince, A. (1980). A metrical theory for Estonian quantity. Linguistic Inquiry, 11(3), 511-562. http://www.jstor.org/stable/4178178

Prince, A. (1990). Quantitative consequences of rhythmic organization. Citeseerx, 26(2), 355-398. http://citeseerx.ist.psu.edu/viewdoc/download?doi=10.1.1.1066.3139\&rep=rep1\&type=pdf

Prince, A., \& Smolensky, P. (2004). Optimality Theory: Constraint interaction in generative grammar. Blackwell Publishing. https://doi.org/10.1002/9780470756171.ch1

Prochazka, T. (1988). Saudi Arabian dialects. Routledge.

Roca, I. (1994). Generative phonology. Routledge.

Sakarna, A. (2013). A Proposed Model of Optimality Theory for Jordanian Arabic Broken Plurals. English Language Teaching, 6(1), 48-55. https://doi.org/10.5539/elt.v6n1p48

Selkirk, E. (1980). The role of prosodic categories in English word stress. Linguistic Inquiry, 11(3), 563-605. Retrieved from http://www.jstor.org/stable/4178179

Steriade, D. (1982). Greek prosodies and the nature of syllabification. Doctoral dissertation, Massachusetts Institute of Technology. Retrieved from https://dspace.mit.edu/bitstream/handle/1721.1/15653/10583995-MIT.pdf?sequence=2

Tesar, B. (1997). An iterative strategy for learning metrical stress in Optimality Theory (pp. 615-626). In Proceedings of the 21st Annual Boston University Conference on Language Development. Retrieved from https://scholarship.libraries.rutgers.edu/discovery/fulldisplay/alma991031550014904646/01RUT_INST:Res earchRepository

Watson, J. (2011). Word stress in Arabic. The Blackwell companion to phonology, Wiley-Blackwell, 2990-3019. https://doi.org/10.1002/9781444335262.wbctp0124

\section{Copyrights}

Copyright for this article is retained by the author, with first publication rights granted to the journal.

This is an open-access article distributed under the terms and conditions of the Creative Commons Attribution license (http://creativecommons.org/licenses/by/4.0/). 